\title{
Innovative Thinking in Higher Vocational Colleges' Physical Education
}

\author{
Wenxian Lin* \\ Quanzhou Vocational College of Arts and Crafts, Quanzhou 362500, Fujian Province, China \\ *Corresponding author: Wenxian Lin, lwx1314lln@163.com
}

\begin{abstract}
General Secretary Xi Jinping pointed out that in a country, if the youth is strong, the country would be strong and if sport is a strong entity in China, the country will be strong as well. In regard to that, promoting the continuous development of sports in China is an important aspect of the great rejuvenation of the Chinese nation. The "Healthy China 2030" plan is a program in the creation of a "healthy China." With the current state of physical education in higher vocational colleges, three aspects are included in the innovative thinking of higher vocational physical education which are strategies for the challenges and impacts faced by physical education teachers in higher vocational colleges, achieving exquisite indicators in physical education as the ultimate goal of vocational colleges, as well as piquing the interest of higher vocational colleges for learning in regard to physical education courses.
\end{abstract}

Keywords: Higher vocational colleges; Physical education; Innovative thinking

Publication date: June 2021; Online publication: June 30, 2021

\section{Introduction}

General Secretary Xi Jinping stated that, “A strong youth will make China strong, and strong sports will make China strong. Promoting the continuous development of my country's sports is an important part of the great rejuvenation of the Chinese nation." The "Healthy China 2030" is a subsystem based on an action plan for the construction of a "healthy China" and this subsystem in regard to higher vocational colleges refers to physical education. ${ }^{[1]}$ At present, colleges' physical education emphasizes on "health first," "lifelong physical education," and "quality education" as their essential ideology. The traditional teaching concepts can no longer meet the requirements of the development and reform of modern colleges' physical education. Therefore, it must be established in line with time and new thinking of teachings should be based on educational development levels with specific requirements. The understanding of physical education needs to be transformed from low to high levels, from closed to open, from single to multiple, and from partial to overall as there are major changes in its concepts. ${ }^{[2]}$

\section{Challenges and impacts faced by physical education teachers in higher vocational colleges}

Generations are changing and the world trends are radically evolving. With the rapid advancement of knowledge and technology, widespread dissemination of information, increasing productivity, globalization, market competition, and the eager pursuit of social development have a strong impact on education. In terms of philosophy, operation, and practice, fundamental changes have taken place. Therefore, education transformations are inevitable. In the era of knowledge economy, in order to enhance competitiveness and being in a state of advantage, the pursuit of innovation has become the key to success. Hence, the term "innovate or die" is no longer alarming. ${ }^{[3]}$ In the past two decades, the global situation has undergone drastic changes. A new era of competition characterized by free, open, transparent, rapid 
changing in addition to complex and diverse values has taken place. This development trend is impacting the direction of education reform in China which includes schools' standards and the profession of teachers. The principle of autonomy is still the biggest change in the modifications of educational policy in regard to schools' operations. Furthermore, with rapid changes in the society, schools are facing external challenges day by day in view of the publics' demand for an excellent, high-quality education which pressurizes schools. In fact, the purpose of physical education in higher vocational colleges is not only to help college students obtain academic achievements but also to help them gain a fulfilling life. Therefore, physical education in vocational colleges today have added value in learning among college students by enhancing their potential in terms of their thinking ability, knowledge, and skills via the socially inclined process of sports education. The innovative teaching of physical education in higher vocational colleges does not only advocate ideas but also, in the practical form. This type of teaching needs to be in tune with correct concepts and implemented in actual environments. Hence, it is necessary to develop high-quality physical education courses in higher vocational colleges while creating positive environments, applying evaluation methods and processes, encouraging and rewarding outstanding performances of teachers, as well as analyzing teaching methods and learning results to achieve performance-compliant results. The topic of reform and development of physical education in higher vocational colleges under rapid social changes has become an extremely important issue today.

\section{Enhance the interest of college students toward physical education in higher vocational colleges}

The purpose of physical education is to support college students in succeeding and not to create an athlete. However, most of the current physical education teaching is based on the traditional teacher-centered teaching method which advocates using motor skills as the main axis and focusing on training students' physique but neglecting their emotional experiences, independent thinking, and problem-solving skills. Physical education teachers in colleges and universities usually teach sports via skills decomposition, practices, piecing together several movements, understanding the overview of the entire education, rules, tactics, as well as sharpening their skills to be more proficient prior competitions. If physical education classes only focus on the learning process of physical fitness and repeated practices, college students would lose interests because it will only create painful experiences. In this way, it is almost impossible to achieve goals. Physical education should maintain skill-level learning, but it also needs to create other learningoriented goals. This is because when college students are unable to feel a sense of accomplishment, it would gradually wipe out their willingness or motivation to learn sports and eventually, their expectations as well as enthusiasm for physical education classes also diminish. Eventually, physical education classes become a stage of performance for a minority of students. This, of course is not in line with the fundamental concept of student-centered higher education, let alone the habit of lifelong exercise.

Therefore, the design and implementation of physical education courses in higher vocational colleges should have an appropriate direction with reasonable thinking so that students would develop an interest in sports. The content taught in physical education courses among higher vocational colleges should be in line with the actual needs of their students. This is the progress that people would want to see when pursuing physical education courses. Physical education curriculum in higher vocational colleges should focus on strengthening students' adaptability so that they would learn quick adaptation to different environments. This education in higher vocational colleges should be strengthened based on its close link with life while the learning contents should emphasize fundamental skills, abilities, and attitudes so that students may cultivate them in their daily lives. Hence, it is essential for the curriculum to touch on life's aspects so that the ideal goal of a lifelong devotion to sports can be achieved. At present, although the development of physical education courses in vocational colleges requires emphasis on the practical concepts of life, the issue lies in the necessary concepts and conditions in their curriculum which would enhance students' 
willingness and motivation to learn and eventually, achieving effective learning. If the contents and teaching materials of physical education in higher vocational colleges can be presented in an interesting manner with a livelier class environment, it will benefit the students' learning process. Although the layout of physical education courses in various vocational colleges have their practicalities, the technical aspects are difficult and sports skills themselves are not easy to learn which result in demotivation among college students. Therefore, the layout of physical education courses in higher vocational colleges should be improved and navigated in the direction of being more fun as well as easier to learn, understand, and apply.

\section{Innovation and refinement of physical education in higher vocational colleges}

In order to cultivate competitiveness in future college students, it is urgent to provide exquisite teaching qualities which comes from endless creativity. ${ }^{[4]}$ Exquisite educational connotation supplemented with excellence, performance, science and technology, as well as innovation are necessary in the design blueprint in order to inspire creativity. This, in turn would allow horizontal and vertical developments as well as extensions while creating excellence and refinement with the concept of scaffolding. Creativity can be seen all around. Starting from oneself, with a little observation and thinking, it is possible to regain creative imaginations. There are four exquisite indicators of a creative higher vocational sports.

The first is the excellence of higher vocational sports. Higher vocational sports emphasize the pursuit of excellence and quality improvements. The educational goal is based on the purpose of teaching but not in terms of classrooms. Firstly, the strategy of teaching in accordance with students' aptitude is adopted so that college students may have opportunities for self-realization. Second, the excellence of refined education is the principle of equal emphasis on quality. On the one hand, the emphasis is on the provision of more educational opportunities while on the other hand, the emphasis is on appropriate curriculum contents, promotion of teachers' morale, and the overall improvement of college students' quality.

The second is the performance of higher vocational sports. Higher vocational sports emphasize highquality educational output, attach value to educational contents, and the process performance in teaching activities. The process performance indicates that when educators initiate educational activities, they need to emphasize the process, methods, and teaching skills, in addition to be able to move the other party to achieve better teaching results.

Third, the technologicalization of higher vocational sports. In order to achieve high-quality educational output, it is necessary to integrate cutting-edge technologies, make full use of information, as well as audiovisual media which is an indispensable weapon for excellent teaching.

Lastly, the innovation of higher vocational sports. Knowledge and information are tools and materials of creativity while innovation is its soul. Innovation is a form of organizational, systematic, and idealized change. It relies on rigorous analysis with continuous research and improvement while introducing contents and methods of education. This creates a breakthrough of the status quo as well as an enhancement of college students' interests and effectiveness in learning. ${ }^{[5]}$

If physical education is to cultivate the creativity of college students, it needs to first change the authoritative style teaching among teachers in colleges and universities, gradually decentralize the room for autonomy, and allow college students to learn independently. In simpler terms, it requires a change from an authoritative teacher deciding on teaching materials, teaching, evaluating, and guiding to self-taught college students. It is an excellent foundation before allowing college students to practice, judge, and decide by themselves, and eventually create, design, and learn by themselves. Higher vocational physical education teachers should encourage college students to transform their traditional ideology and encourage them to conceive innovative ideas in order to seek breakthroughs which eventually leads to students cultivating a divergent thinking from various aspects and perspectives, associating, and finally, produce meaningful and creative learning or performances. In the curriculum, education needs to be innovative and 
fun in which the prerequisite is that teachers should be able to think creatively to stimulate college students' creative thinking skills. If teachers themselves lack creativity, lessons would then be all empty talks. College students do have innovative motives and ideas, however, if there are no opportunities to practice them, it would be pointless. Innovation is always integrated with independent learning. In higher vocational physical education classroom lessons, teachers need to learn to "let go" by allowing students to have moderate autonomy and freedom, permitting them to take on protagonist roles in classrooms, and improve their innovation abilities. Therefore, in the teaching process, it should be student-centered and college students should be given the freedom to decide on the learning time and space in order to cultivate independent and innovative spirits. ${ }^{[6]}$ For example, in games lessons, the teacher can assign a small rubber ball to each group of students to create activities by themselves. In simpler terms, the students would be required to use the small rubber ball as the focus in creating activities that everyone enjoys. This is beneficial as students would brainstorm and contribute new ideas. After a period of discussion and selection, students would have created a variety of games such as pitching scoring, running with two legs, naming the ball, hitting an active target, catching the ball, and hitting people with the ball. Through these activities, the main role of college students and the enthusiasm for independent learning are effectively enhanced which would cultivate their creative thinking skills and improve their experiences and practical skills. ${ }^{[7]}$

In order to achieve the desired effect of college physical education in higher vocational colleges, the evaluations and arrangements of the most suitable course content have become issues. First of all, textbooks should be modified to eliminate boring and irregular contents. By organizing lively and interesting games, it can create motivation among college students for learning. From motivations to motivations, the passion for learning would continue. Following that, by inviting sports professionals to discuss, research, and implement these courses with the instructors would also benefit in achieving goals. An ideal physical education does not only involve pure physical activities, but it also cultivates college students to improve in terms of cognition as well as their skills in those activities, viewing, driving, etc. to achieve the goal of understanding sports and developing their interests in them. To achieve the realm of a healthy and vigorous society with "sports everywhere, everyone loves sports," the mission should be undertaken by sports workers. However, it is also a goal that everyone is willing to promote and work hard for to see achievable. The promotion of sports largely depends on the implementation of physical education in higher vocational colleges which increases college students' cognition and enhance their motivation to participate. This is the most important starting point, and it is the basis of whether the public would enjoy sports in the future. These topics discussed are essential and the education department needs to consider and analyze them.

\section{Conclusion}

In the past, physical education lacked applied thinking training and focused only on teachers' demonstrations and students' imitation practices. Such teaching methods do not only hinder college students' ability to think and innovate but also cause them to lose interest in the application of physical education. ${ }^{[10]}$ More freedom in physical education should be provided for open imagination and thinking so that college students would be able to learn independently and enjoy sports. Only in this way, sports can be integrated in their daily lives and become more prevalent in the society.

The determining factor of the connotations and essence of physical education are in the role of the teachers. Teachers are the main players while students are the focus. Teachers need to face changes bravely while college students need to seek a common ground in these changes based on a constant point of reference which is the quality. It is the highest guiding principle of physical education in higher vocational colleges. ${ }^{[8]}$ Through activities, teachers' innovations would enhance the interests and motivations among college students as well as create a sense of identity in the physical education curriculum. Not only does it achieve the goal of effective teaching, but it would also deeply affect the psychological aspects of college 
students and the positive development of physical, social, and intellectual education. Innovative thinking teachings focus on the integration of daily life experiences which would stimulate the students' motivations and interests in learning. It uses teacher-student interactions to inspire creativity among college students and encourages learning from mistakes. Everyone then would have the opportunity to be a protagonist. On the other hand, teachers would be able to provide guidance in a timely manner and expand their teaching materials; hence, effectively achieving teaching goals. The contents of physical education are mainly used to teach college students to engage in physical exercises. If teachers themselves actively participate in physical activities and enjoy sports through creative teachings, students' fear of physical education would be reduced and in turn, stimulate their interest for continuous learning. In this way, regular exercise habits and attitudes can be cultivated so that not only the nation's fitness would be promoted but it would also take root while contributing to the rid of civilization diseases caused by sedentary lifestyles; hence, indirectly reducing social medical costs. The educational policy of higher education is a turning point for the country's continuous future development. Innovative thinking teaching is indeed a method worth promoting. This mode of teaching can be said to be a beacon for the education sector. In physical education, it is necessary to constantly summarize experiences, boldly trying, actively exploring, and innovating to strive toward cultivating college students' innovative ability. ${ }^{[9]}$ By allowing college students to be exposed to various education and teaching, it helps them to develop a good sense of sports innovation as well as to promote a wholesome growth of body and mind in adapting to the needs of modern physical education.

\section{Disclosure statement}

The author declares no conflict of interest.

\section{References}

[1] Liu MJ, 2018, Research on Chinese youth sports public policy under the background of "Healthy China 2030”. Sports Science, 2(38): 91-6.

[2] Zhao JJ, 2004, New thinking of physical education in colleges and universities. Journal of Zhuzhou Institute of Technology, 4(18): 69-70.

[3] Wu QJ, 2002, The important ideas and implementation strategies of creative teaching. Taiwan education, (4): 2-8.

[4] Li Y, Zhou MJ, 1998, New thinking in physical education. Journal of Guangxi Normal University (Natural Science Edition), (8): 87-91.

[5] Gui SD, 2010, Research on the quality assurance management strategy of Taiwan's basic education taking Taipei city as an example, East China Normal University, Wuhan.

[6] Qu Z, Zheng HJ, 1988, On the development and conception of my country's college reform. Sports Science, (4): 43-9.

[7] Le ZJ, 2013, Talking about how to cultivate students' innovative ability in physical education. Hubei Today (Late Period), (11): 101.

[8] Wu GJ, 2015, The application of creative thinking teaching method in tennis teaching. Contemporary Sports Science and Technology, (2): 155-6.

[9] Qu BN, 1988, Collected works of education (physical education volume), People's Education Press, Beijing.

[10] Zhou WJ, 2012, On the cultivation of students' innovative ability in physical education. Network Herald Online Education, (18): 102. 